\title{
A note on clinical presentations of amebic liver abscess: an overview from 62 Thai patients Viroj Wiwanitkit
}

Address: Department of Laboratory Medicine, Faculty of Medicine, Chulalongkorn University Bangkok 10330, Thailand

E-mail: wviroj@pioneer.netserv.chula.ac.th

Published: 31 July 2002

BMC Family Practice 2002, 3:13
Received: 17 April 2002

Accepted: 31 July 2002

This article is available from: http://www.biomedcentral.com/147I-2296/3/13

(C) 2002 Wiwanitkit; licensee BioMed Central Ltd. This article is published in Open Access: verbatim copying and redistribution of this article are permitted in all media for any non-commercial purpose, provided this notice is preserved along with the article's original URL.

\begin{abstract}
Background: Amebic liver abscess is a tropical disease with a wide spectrum of clinical presentations. Given the often nonspecific nature of the complaints related to amebic abscess, a retrospective review of patients with confirmed disease to recognize the most common patterns of presentation is useful. Here, we study the clinical presentations of 62 Thai patients with amebic liver abscess. We also compare the clinical presentations of Anti HIV seronegative and Anti HIV seropositive patients.
\end{abstract}

Methods: A retrospective case review was carried out for 62 Thai patients who had been diagnosed with amebic liver abscess. Clinical information was collected, including symptoms and signs, location and number of abscesses. The Anti HIV serology laboratory investigation was also reviewed.

Results: According to our study, the common clinical symptoms and signs are abdominal pain ( 85.5 $\%$ ), fever and chills $(74.2 \%)$, and abdominal tenderness $(69.4 \%)$. The location of the abscess was predominantly in the right lobe (74.2\%), and most of patients had a single abscess (77.4\%). Similar trends in clinical presentations were observed in both Anti HIV seropositive and Anti HIV seronegative subjects.

Conclusions: In conclusion, the clinical presentations of our amebic liver abscess patients were similar to those in previous reports. A similarity to those in the pyogenic liver abscess patients can be observed. Nevertheless, we could not detect important significant differences in the clinical presentations between Anti HIV seropositive and Anti HIV seronegative groups of patients.

\section{Background}

Significant differences exist in the prevalence of most gastroenterological emergencies in tropical countries compared with temperate countries [1]. Both ethnic and environmental, often clearly defined geographically, factors are relevant. Amebiasis is a widespread parasitic disease caused by Entamoeba histolytica. This protozoan organism is the third leading parasitic cause of death in the developing world and is an important health risk to travelers in endemic areas [2]. Amebiasis most commonly results in asymptomatic colonization of the gastrointestinal tract, but some patients may develop intestinal invasive disease or extraintestinal disease. The most common extraintestinal manifestation is that of a liver abscess [2]. This infection is common throughout the world and can be associated with life-threatening consequences [2-5]. 
Concerning the amebic liver abscess, the pathogenic organism is carried through the blood to the liver where the abscess is formed. Patients may or may not have symptoms of intestinal infection concurrently with liver abscess [3-5]. This infection is present worldwide, but is most common in tropical areas where crowded living conditions and poor sanitation exist. Transmission occurs through ingestion of cysts in fecally contaminated food or water, use of human excrement as fertilizer, and personto-person contact. The incidence is about 1 out of 100,000 people for amebic liver abscess [3-5].

Here, the author reports the clinical presentations of the amebic liver abscess in 62 Thai patients. The author also presents some notification on the clinical presentations among the HIV seropositive and HIV seronegative patients in our series.

\section{Methods}

The medical records of in-patients at the King Chulalongkorn Memorial Hospital, Bangkok, Thailand, who had been diagnosed as cases of amebic liver abscess, at some time between January 1992 and December 2001, were retrospectively reviewed. In each case, the abscess was diagnosed on the basis of the abscess cavity's appearance on liver US and/or CT scans, and the recovery of pus from the cavity during needle aspiration or surgery. The amebic liver abscesses were diagnosed by 1) the identification of Entamoeba histolytica by microscopic examination of the pus $(\mathrm{n}=28)$ or 2$)$ the positive results from Entamoeba histolytica indirect hemagglutination (IHA) test $(\mathrm{n}=34)$.

The data collated from the records included the sex and age of each patient, the Anti HIV serology status, the symptoms and signs, the location and the number of abscesses. All recorded data were collected and analyzed using descriptive statistics. Statistical significance level was accepted at P-value equaled to 0.05 . All the statistical analyses in this study were made using SPSS 7.0 for Windows Program.

\section{Results}

In the 10-year admission period investigated, 62 patients were diagnosed as having amebic liver abscesses. In this presentation, these 62 cases - 33 men (53.2\%) and 29 women (46.8\%) - had a mean (S.D.) age of 45.03 (19.92) years (range $=10-88$ years). Of these 62 patients, 23 were Anti HIV seropositive (37.1\%) and 39 were Anti HIV seronegative (62.9\%) (Table 1$)$. Most of the patients were suffering from abdominal pain (85.5\%), fever and chills (74.2\%), and abdominal tenderness (69.4\%; Table 2).

The abscesses detected were usually restricted to the right lobe of the liver (46 cases, $74.2 \%$ ). Only seven $(11.3 \%$ ) of the cases only left-lobe abscesses and nine (14.5\%) had both lobes affected. Among the Anti HIV seropositive group, 17 had abscesses in the right lobe, 4 in the left and 2 in both. As for the Anti HIV seronegative group, 29 had abscesses in the right lobe, 3 in the left and 7 in both.

Forty-eight of the cases $(77.4 \%)$ had a single abscess and $14(22.6 \%)$ had multiple abscesses. Among the Anti HIV seropositive group, 18 had a single abscess and 5 had multiple abscesses. As for the Anti HIV seronegative group, 30 had a single abscess and 9 had multiple abscesses. There is no significant difference in the proportion of cases with multiple abscesses between both groups (Proportional $\mathrm{Z}$ test, $\mathrm{P}>0.05$ ).

\section{Discussion}

Liver abscess is an important tropical gastrointestinal disorder $[1,6]$. The liver abscess is classified mainly into pyogenic and amebic types. Concerning liver amebiasis, the infection starts with an ingestion of amebic cysts, which, after excystation form trophozoits in the small intestine, colonize the bowel lumen and invade the intestinal epithelium resulting in amebic colitis. The spreading to the liver and formation of amebic liver abscesses occurs in one third of the cases [3-5]. Amebic liver abscess have a good prognosis when treated with metronidazole $[2,5]$. An early diagnosis and treatment is therefore important. The diagnosis is made by demonstration of Entamoeba histolytica cysts or ameba in the pus or positive serology $[2,5]$.

Table I: Patients' characteristics in 62 patients with amebic liver abscess

\begin{tabular}{|c|c|c|c|}
\hline \multirow[t]{2}{*}{ Patients' characteristics } & \multicolumn{3}{|c|}{ Group } \\
\hline & All $(n=62)$ & Anti HIV seropositive $(n=23)$ & Anti HIV seronegative $(n=39)$ \\
\hline Age (years) & $45.03 \pm 19.92$ & $45.83 \pm 16.65$ & $44.56 \pm 21.81$ \\
\hline Sex (Male: female ratio) & $33: 29$ & $10: 13$ & $23: 16$ \\
\hline Duration of clinical presentations (days) & $7.31 \pm 0.82$ & $7.30 \pm 0.82$ & $7.33 \pm 0.83$ \\
\hline
\end{tabular}


Table 2: Clinical presentations in 62 patients with amebic liver abscess

\begin{tabular}{|c|c|c|c|}
\hline \multirow[t]{2}{*}{ Clinical presentations } & \multicolumn{3}{|c|}{ Number of patients (\%) } \\
\hline & All & Anti HIV seropositive & Anti HIV seronegative \\
\hline Abdominal pain & $53(85.5 \%)$ & $14(22.6 \%)$ & $39(62.9 \%)$ \\
\hline Fever and chills & 46 (74.2\%) & $18(29.0 \%)$ & $28(45.2 \%)$ \\
\hline Abdominal tenderness & $43(69.4 \%)$ & $14(22.6 \%)$ & $29(46.8 \%)$ \\
\hline Anorexia & $39(62.9 \%)$ & $14(22.6 \%)$ & $25(40.3 \%)$ \\
\hline Hepatomegaly & $37(59.7 \%)$ & $14(22.6 \%)$ & $23(37.1 \%)$ \\
\hline Jaundice & $25(40.3 \%)$ & $9(14.5 \%)$ & $16(25.8 \%)$ \\
\hline Nausea & $23(37.1 \%)$ & $8(12.9 \%)$ & $15(24.2 \%)$ \\
\hline Malaise and weakness & $14(22.6 \%)$ & $4(6.5 \%)$ & $10(16.1 \%)$ \\
\hline Body weight loss & $10(16.1 \%)$ & $4(6.5 \%)$ & $6(9.6 \%)$ \\
\hline Dyspnea & $7(11.3 \%)$ & $2(3.2 \%)$ & $5(8.1 \%)$ \\
\hline
\end{tabular}

\footnotetext{
* There is no significant difference in the proportion of patients with each clinical manifestation between Anti HIV seropositive and Anti HIV seronegative groups.
}

This infection can demonstrate a wide spectrum of clinical presentations from no complaints to arrest [7-11]. Malnutrition, liver cirrhosis and alcoholism have been reported to be an important factor in causing the infected person to have more severe clinical presentations [2-5]. Given the often nonspecific nature of the complaints related to an amebic abscess, a retrospective review of patients with confirmed disease to recognize the most common patterns of presentation is useful [7-11]. Nevertheless, there had been no study comparing the clinical presentations of the amebic liver abscess in Anti HIV seronegative comparing to Anti HIV seropositive cases. Therefore, we designed this study to review the clinical presentations of the Thai patients with amebic liver abscess. A comparison of clinical presentations between Anti HIV seronegative and Anti HIV seropositive cases was also made.

Concerning the Anti HIV serology, 23 cases were Anti HIV seropositive (37.1\%) and 39 were Anti HIV seronegative $(62.9 \%)$. The average age of both groups was not significantly different (Unpaired T-test, $\mathrm{P}>0.05$ ). The proportion of male or female subjects in both group was not statistically significantly different (Proportional Z test, P > 0.05). There was no significant difference in the duration of clinical presentations between both groups either (Unpaired T-test, $\mathrm{P}>0.05)$. Of interest, generally, invasive amebiasis as amebic liver abscess rarely occurs in HIV seropositive individuals and has not been regarded as a disorder for concomitant HIV infection. One of the possible explanations is the fact that most of the previous studies were in temperate countries, which is not the endemic area of amebiasis [12]. Our findings support the observation of Liu that amebic liver abscess can be an important gastrointestinal problem for HIV infection in the Far East [13].

According to our series, the findings about the clinical symptoms and signs in our patients were similar to those in the previous reports $[2,5,7]$. The three most common findings are abdominal pain (85.5\%), fever and chills $(74.2 \%)$, and abdominal tenderness (69.4\%). These three common findings are present in both Anti HIV seropositive and Anti HIV seronegative cases (Table 1). These clinical manifestations are similar to those in pyogenic liver abscess patients [8-11].

Like in the previous studies $[2,5,7]$, the abscesses were located predominantly in the right lobe of the liver $(74.2$ $\%)$. Regarding the number of abscesses, most of our patient had single abscess $(77.4 \%)$. These findings are similar to the reported characters among the pyogenic liver abscess patients [8-11]. In addition, these trends are similar for both Anti HIV seropositive and Anti HIV seronegative.

In conclusion, the clinical presentations of our amebic liver abscess patients were similar to those in previous reports. The similarity to those in the pyogenic liver abscess patients can also be observed. Nevertheless, we could not demonstrate important significant difference of the clinical presentations between Anti HIV seropositive and Anti HIV seronegative groups in our patients.

\section{Competing interests}

None declared. 


\section{References}

I. Cook GC: Gastroenterological emergencies in the tropics. Baillieres Clin Gastroenterol I991, 5:86I-86

2. Hughe MA, Petri WA WA Jr: Amebic liver abscess. Infect Dis Clin North Am 2000, 14:565-82

3. Falaiye JM, Okeke GC, Fregene AO: Amebic abscess in the cirrhotic liver. Gut 1980, 21:161-3

4. Rustgi AK, Richter JM: Pyogenic and amebic liver abscess. Med Clin North Am 1989, 73:847-58

5. Nunes A, Varela MG, Carvalho L, Ranchhod R, Saavedra JA: Liver amebiasis. Acta Med Port 2000, I3:337-43

6. Reeder MM: Tropical diseases of the liver and bile ducts. Semin Roentgenol 1975, 10:229-43

7. Hoffner RJ, Kilaghbian T, Esekogwu VI, Henderson SO: Common presentations of amebic liver abscess. Ann Emerg Med 1999, 34:35I-5

8. Kuo CM, Kuo $\mathrm{CH}$, Changchien CS: Liver abscess in patients with cirrhosis of the liver: a I 2-year experience. J Gastroenterol 200I, 36:552-6

9. Bissada AA, Bateman J: Pyogenic liver abscess: a 7-year experience in a large community hospital. Hepatogastroenterology 1991, 38:317-20

10. Branum GD, Tyson GS, Branum MA, Meyers WC: Liver abscess: changes in etiology, diagnosis, and management. Ann Surg 1990, 2 I 2:655-62

II. Chiu CT, Lin DY, Wu CS, Chang-Chien CS, Sheen IS, Liaw YF: A clinical study on pyogenic liver abscess. J Formos Med Assoc 1987, 86:405-12

12. Seeto RK, Rockey DC: Pyogenic liver abscess: changes in etiology, management, and outcome. Medicine (Baltimore) 1996, 75:99-113

13. Liu C], Hung CC, Chen MY, et al: Amebic liver abscess and human immunodeficiency virus infection: a report of three cases. J Clin Gastroenterol 200I, 33:64-8

\section{Pre-publication history}

The pre-publication history for this paper can be accessed here:

http://www.biomedcentral.com/1471-2296/3/13/prepub

Publish with BioMed Central and every scientist can read your work free of charge

"BioMedcentral will be the most significant development for disseminating the results of biomedical research in our lifetime."

Paul Nurse, Director-General, Imperial Cancer Research Fund

Publish with BMC and your research papers will be:

- available free of charge to the entire biomedical community

- peer reviewed and published immediately upon acceptance

- cited in PubMed and archived on PubMed Central

- yours - you keep the copyright

Submit your manuscript here:

http://www.biomedcentral.com/manuscript/
BioMedcentral.com editorial@biomedcentral.com 